СОЛОВьЁВ Александр Иванович - доктор политических наук, профессор; профессор факультета государственного управления Московского государственного университета им. М.В. Ломоносова (119991, Россия, г. Москва, Ломоносовский пр-кт, 27, корп. 4 «Шуваловский»; alekssol21@gmail.com; solovyev@spa.msu.ru)

\title{
КУЛЬТУРА И ПОЛИТИКА: КОНТУРЫ ВЗАИМОДЕЙСТВИЯ В СОВРЕМЕННОЙ РОССИИ
}

\begin{abstract}
Аннотация. В статье автор поднимает вопрос взаимоотношений российских властей и общества на культурном поле, обозначая существующие вызовы и риски. В частности, автор обрисовывает проблему слабой заинтересованности властей в смягчении и нейтрализации политических последствий культурных противоречий, а также подавление демократических тенденций, пренебрежительное отношение к культурно-ценностным потребностям населения. В решении этих проблем автор видит крайне важный аспект гармоничного прогресса общества и государства, в выводах статьи приходя к возможным путям разрешения намеченных конфликтов.
\end{abstract}

Ключевые слова: политика и культура, либерализм, пропаганда, оппозиция, общегражданская солидарность, культурные стандарты и ценности, политический режим

$\Phi$ актор культуры имеет для политики непреходящее значение. Ее ценностно-гуманистические основания хотя и индифферентны по отношению к реальной политике, но, тем не менее, в долгосрочной перспективе именно они определяют типичный характер поведенческих паттернов элитарных и неэлитарных слоев, долгосрочное видение любых форм организации власти. Будучи явлением широкого социального масштаба, культура не всегда обретает политические очертания активности человека, скорее отражая кризисный характер политического участия как формы повседневной активности. Одним словом, политические процессы и культурная динамика являют собой два разных потока человеческой жизни, лишь частично пересекающихся в точках напряжения властных отношений. Тем не менее политика была и остается тем показателем индивидуальной и общественной свободы, которая позволяет человеку усваивать значимый для него социальный опыт, выстраивая отношения и с властью, и с носителями иных ценностей и предпочтений.

В то же время, как показывает практика, характер ценностных предпочтений человека (в т.ч. в его групповых формах) был и остается источником различных (в т.ч. и реакционных) политических проектов, целей и многочисленных спекуляций со стороны тех сил, которые по разным причинам стремятся использовать коммуникативный и мобилизационный потенциал культуры. Под таким влиянием публично подогреваемые расхождения культурных предпочтений нередко обретают характер непримиримых идейно-политических позиций, не исключающих агрессивные действия против оппонентов. Действия такого рода не лучшим образом отражаются на содержании смысловых и идейно-ценностных ориентаций человека, создавая искусственные препятствия для поиска идентичности и мешая аутентичному усвоению общественного и личного опыта. Причем первой жертвой политизации культурных этносов в сложно организованных обществах становится общегражданская солидарность, а впоследствии - и политическая стабильность в государстве.

В этом смысле современное российское общество с его разнообразным социокультурным и политическим ландшафтом хорошо иллюстрирует ситуацию 
подобного рода. Власти (с учетом групповой сегментации правящей элиты) и их конкуренты постоянно пытаются использовать мобилизационный капитал культуры в своих узкогрупповых интересах. И хотя назначение и общегражданский характер ответственности властей существенно отличаются от целей их конкурентов (предполагая, в частности, снижение политических трений и повышение внутренней сплоченности общества), их активность в этом вопросе является главным источником искусственной политизации культурного поля.

Конечно, можно было бы сослаться на целый ряд обстоятельств, препятствующих, скажем так, «гуманистически-нормативному» решению задачи. Это и высокий уровень поляризации ценностных предпочтений у различных слоев населения, и наличие многочисленных социально-экономических противоречий ${ }^{1}$, и широкое распространение социальных болезней как в элитарных (например, масштабная институциональная коррупция), так и в неэлитарных (анархизм, шовинизм, ксенофобия, радикализм и др.) кругах, и враждебная политика ряда зарубежных стран, и т.д. Возможно, по этим причинам отечественная политика представляет собой весьма жесткое социальное пространство, где полным приоритетом обладают интересы мощных (в т.ч. и латентных) группировок правящего класса, а не публичные аргументы, апеллирующие к общественным ценностям, где граждане принципиально не способны оказывать влияние на институты власти.

В то же время практика показывает, что власти слабо озабочены поиском путей для смягчения и нейтрализации политических последствий культурных противоречий. Более того, они и не особо озабочиваются какими-то особыми инструментами поддержания выгодной обществу межкультурной коммуникации, ограничиваясь поддержкой стандартов традиционалистского типа мышления, резко контрастирующего с задачами общественного развития. Благодаря этому в пространстве российской культуры постоянно воспроизводятся ценности манихейского мировосприятия, архаического коммунитаризма (отечественная разновидность артельного принципа совместной жизни), патримониализма; притерпелость людей к ограниченности средств существования, нелюбовь к правовым формам законности, незаинтересованность граждан в контроле за правящими структурами. По сути, эти культурные стандарты активно используются властями для сохранения устраивающей их стабильности.

Однако надо иметь в виду, что власти, поддерживая стереотипы утопического мировосприятия массового сознания и опираясь на них, по сути, укрепляют принципы догосударственного порядка, предполагающие не только оправдание высокой концентрации власти, но и нарастание рисков столкновения этой культурной массы с непрерывным усложнением общества. И, как показала история, реакция патриархальной культуры в этом случае может спровоцировать коренные политические подвижки и иметь самые разрушительные последствия ${ }^{2}$.

1 Банальным и одновременно печальным подтверждением этому служит катастрофическая, небывалая в истории страны социально-экономическая дифференциация населения (к примеру, почти $90 \%$ всех финансово-экономических активов общества принадлежат $2 \%$ населения).

2 Уместно вспомнить в этой связи, что первые русские революции как раз и были «политическим ответом» массы, столкнувшейся с не укладывающимся в стереотипы массовой культуры усложнением индустриального мира. И единственным ответом на такой конфликт стала организованная большевиками общероссийская бойня, приведшая к катастрофическим последствиям для страны и ее населения. Так что только красный террор стал инструментом стабилизации отношений государства и общества. 
Однако понятно, что основным инструментом попыток сохранить симпатии традиционалистски настроенных слоев населения является агрессивная телепропаганда. Подыгрывание традиционалистским стереотипам неразрывно совмещается с попытками умиротворения общества и отвлечения его от насущных внутренних проблем, активным насаждением разнообразных мифов, дискредитацией любых форм оппонирования властям. При этом пропагандируемые цели развития и принципы «единства нации» подчас полностью отрываются от реальности, сохраняя лишь свою сугубо символическую форму. Причем на этом фоне крайне парадоксальным выглядит и непримиримая борьба официальных пропагандистов (действующих, заметим, в рамках конституционно закрепленной в стране модели демократии) с идеями и ценностями либерализма со всем набором его принципиальных принципов и норм. При этом даже первые лица государства поспешили констатировать «смерть» либерализма.

Одним словом, вместо популяризации рационального и гуманистического подхода к жизни и ценностям общества людям предлагают всевозможные «духовные скрепы», противостоящие «тлетворному влиянию» и разложению «подлинной» отечественной «духовности». С культурологической точки зрения эти постулаты являются откровенным распространением норм имперского национализма, приоритета коллективного актора, критики рационализма и Запада, государственнического инстинкта. Однако в политическом отношении эти идеи используются для распространения и насаждения норм официального, но, по сути, ложного патриотизма, основанного на идеализации государства и правящего режима, а не на любви к Родине.

Руководящей политической идеей власти, поддерживающей курс на укрепление культуры традиционализма, условно говоря, стала идеология «нашизма», разделяющая людей на «своих» и «чужих», по умолчанию устанавливающая негласные политические приоритеты для сторонников, а для противников и критиков режима - принципиальные ограничения в их возможностях, правах и свободах. Однако такая линия является не только и не столько средством выдавливания на политическую периферию оппозиции, сколько инструментом дискредитации несогласных, ограничения прав для всех тех, кто стремится сохранять собственную (причем абсолютно легальную) позицию. Подчеркнем, что такая линия не просто ведет к нарастанию общественной конфронтации, но и последовательно разрушает атмосферу общегражданской солидарности, попутно уничтожая основные механизмы саморазвития культуры, базирующейся на поощрении индивидуальной саморефлексии и критическом усвоении общественного опыта.

С собственно культурной точки зрения главной жертвой такой политики становится общегражданская идентичность, демонстрирующая как усиление распада общегражданской солидарности, так и нарастание социальной глухоты различных сообществ по отношению друг к другу. По сути, повсеместно распространяются формы ложной идентичности (обретение людьми приверженности групповым принципам в ущерб другим), в политическом измерении они превращаются в основание попустительства несправедливости и беззаконию. Следуя тактике закрытости, культурные локалитеты становятся некоммуникабельными по отношению другу к другу, превращая самозакукливание отгороженных друг от друга субкультур в основной механизм духовного саморазвития общества.

Как можно наблюдать, все эти культурные механизмы и практики оказывают самое разрушительное воздействие на ядро человеческой культуры - ценности гуманизма, которые все больше и больше подрываются нормами агрессивно- 
насильственного отношения к жизни и власти. Не приходится удивляться, что общество, более 70 лет находившееся под гнетом коммунистической диктатуры, с трудом преодолевает (а в ряде случаев и сохраняет) наследие этого режима, а власти никоим образом не стремятся развенчать в сознании граждан пагубность этой формы правления. В отличие от Германии, в России не проводилась политика денацификации (которая и на немецкой земле не сразу дала какие-то значимые результаты в плане развенчания тоталитарной системы), и в широких слоях населения не только сохранились различные мифы сталинского режима, но и убежденность в правоте силы над разумом, а власти - над человеком. Поэтому и сегодня принципы гуманизма и справедливости, разума и веры в человеческое достоинство сталкиваются со стереотипами тех сообществ, которые не ценят уникальность жизни и презирают достоинство личности, демонстрируют органическое неприятие общечеловеческих стандартов (уважение к законности, чувство собственного достоинства, взаимной ответственности, гражданского долга и пр.). Не случайно поэтому, что практики «своего» государства ценятся выше принципов свободы и справедливости, а ответственность власти перед гражданами рассматривается как абсолютно конъюнктурная позиция (поэтому и критика в адрес отечественных высокопоставленных коррупционеров рассматривается как покушение на «интересы государства»).

Конечно, надо признать, что традиционализм, даже будучи доминирующим субкультурным образованием, не является единственным фактором, провоцирующим политические цели. Культура России носит гибридный характер, сохраняя как мировоззренческие конфликты (шовинизма и интернационализма), но и противоречия среднего уровня (регионально-этнического соперничества, москвоборчества). С политической точки зрения это означает, что в стране существует культурная основа альтернативности общественного развития. Однако это положение скорее вызывает определенную тревогу, поскольку заторможенная система межкультурных контактов (ограниченных соображениями лояльности к власти и исповедуемыми руководством убеждениями) сохраняет риски углубления культурных расколов, в свою очередь, используемых для активизации политических конфликтов, особенно если учесть отсутствие правовой базы для коммуникации граждан разной ценностно-ориентационной стилистики (например, закона об оппозиции), сохранение возможностей для произвольной дискриминации различных фигур и групп (что, впрочем, полностью наследует российскую традицию признания права только за «большинством», народом в целом, и игнорирует право меньшинств).

Власти не только не выполняют свою миссию, состоящую в возвышении сознания людей до принципов гуманизма и справедливости, но подчас дискредитируют эти идеи и нормы, возможно, даже не осознавая последствий своих действий. Власти не доверяют людям свободно выбирать свои жизненные приоритеты, и поэтому задачи самовоспроизводства правящего режима заслоняют для них и перспективы развития страны, и возможности культурной эволюции российского общества. Распространяя практики точечного правоприменения и избыточного административного давления на общество, власти переходят за ту черту свободного самоопределения человеком своей жизненной траектории, которая превратила большевиков в пораженцев и исторических неудачников. Одним словом, нельзя забывать, что основными жертвами политических баталий являются обыватели, обычные граждане, у которых власти ради собственного благополучия отнимают жизнь и перспективы.

Коротко говоря, сегодня российские власти используют такие техноло- 
гии политического управления социумом, которые крайне губительны как для повседневной жизнедеятельности человека, так и для развития культуры общества. В конечном счете, это становится препятствием и для политического процесса в целом, и для развития общества как такового.

Понятно, что избавиться от таких последствий «культурной» политики государства и использования властями политического капитала культуры можно только путем поощрения демократических форм взаимоотношений государства и общества. Однако перспективы такого развития событий пока не просматриваются. Более того, новые шаги властей (усиление контроля над виртуальной сферой, намерения на конституционной основе встроить местное самоуправление в вертикаль власти, повышение уровня административнополицейского контроля и т.д.) не дают оснований считать, что культурное поле станет ареной солидаризации государства и общества. По крайней мере, пока пространство свободы как пространство культурных экспериментов (являющееся единственной основой развития и гуманизации ценностных ориентиров человека) только сокращается. И на этом фоне политические формы обретают все те же коренные разломы культурного поля (духовности и черносотенства, гуманизма и радикализма, ксенофобии и толерантности и т.д.), которые испытывали российскую судьбу, нередко обретая форму откровенного мракобесия.

Не стоит, видимо, говорить, что в таких условиях не только падает доверие населения к институтам государства, но и нарастает отчужденность граждан от государственной власти. Как итог - вместо патриотических настроений распространяется сервилизм и начетничество, нарастают страхи и недоверие людей к способностям государства поддерживать правовой порядок, и, в конечном счете, развивается культура негражданственности. При этом главными заложниками такой ситуации становятся поколения молодых россиян, их жизненные перспективы и надежды на установление политической демократии в своей стране.

Статья публикуется при поддержке Школы молодого этнополитолога в Республике Башкортостан (грант Фонда президентских грантов 19-2-022447).

SOLOVIEV Aleksandr Ivanovich, Dr.Sci. (Pol.Sci.), Professor; Professor of the Faculty of Public Administration, Lomonosov Moscow State University (bld. 4 «Shuvalovsky», 27 Lomonosovsky Ave, Moscow, Russia, 119991); (alekssol21@gmail.com; Solovyev@spa.msu.ru)

\section{CULTURE AND POLITICS: THE CONTOURS OF INTERACTION IN MODERN RUSSIA}

\footnotetext{
Abstract. In the article, the author raises the question of the relationship between the Russian authorities and society on the cultural field, outlining the existing challenges and risks. In particular, the author speaks about the low level of concern on the part where the authorities need to mitigate and neutralize the political consequences of cultural contradictions, where they suppress democratic trends and neglect the cultural and value needs of the population. At this point, the author sees an extremely important aspect of the harmonious progress of society and the state, and in the end he formulates possible ways of resolving the outlined conflicts.

Keywords: politics and culture, liberalism, propaganda, opposition, civil solidarity, cultural standards and values, political regime
} 